Title: Classroom Discourse

Name: Amy B. M. Tsui

Affiliation/Address: Professor Amy B. M. Tsui

Faculty of Education

The University of Hong Kong

Pokfulam Road

Hong Kong SAR

People's Republic of China

Phone: (852) 28592517

Fax: (852) 25172100

E-mail: bmtsui@hku.hk

Key words: input, interaction, output, sociocultural, ecological, activity theory 
Classroom Interaction / ABMT /p. 2

\section{CLASSROOM DISCOURSE}

The term "classroom discourse", as used in this review, refers to all forms of discourse that take place in the classroom. It encompasses the linguistic as well as the nonlinguistic elements of discourse. The former includes the language used by the teacher and the learners, as well as teacher-learner and learner-learner interactions. The latter includes paralinguistic gestures, prosody and silence - all of which are integral parts of the discourse. The linguistic and non-linguistic elements constitute the observable dimension of classroom discourse. Studies of classroom discourse have explored factors which play a critical role in shaping classroom discourse. These factors pertain to the sociocultural contexts in which the discourse is generated, including the physical environment, the socioeconomic and cultural backgrounds of participants, as well as the psychological dimensions such as their perceptions, emotions, beliefs and orientations. They constitute the unobservable dimension of classroom discourse. Because of the limit of space, this review focuses on SL/FL classrooms, and makes reference to L1 classroom discourse research only when it impacts on SL/FL classroom research.

\section{Early Developments}

Research on classroom interaction and classroom events originated in the field of general education in the 1950s for teacher education purposes. It was motivated by the search for "objective" assessments of student-teachers' performance in the classroom and the identification of "effective teaching". The first major attempt was made by Flanders who proposed a systematic analysis of classroom interaction with an instruction referred to as Flander's Interaction Analysis Categories (FIAC) (Flanders, 1960). Studies of interaction in SL (second language) and FL (foreign language) classrooms began in the 1960s and were largely influenced by Flanders' work. There is a plethora of classroom discourse instruments based on FIAC for language teacher training (see Allwright 1988 for a review of ESL/EFL classroom observation instruments). Early studies of SL/FL classroom interaction were also driven by the need to evaluate the effectiveness of the various FL teaching methodologies in the hope that the "best" method would be identified. The inconclusive findings, however, pointed to the problematic nature of the basic tenets of these studies. It was generally agreed that classroom processes were extremely complex and little understood. The aim of classroom-centered research, it was argued, should be descriptive rather than prescriptive. There was also a consensus that research should focus on not only the teacher's language and behavior, but also the learners’ behavior.

Parallel to the development of research on SL/FL classroom discourse was the research on L1 (first language) classrooms. The impetus for research in this area came from the "language across the curriculum" movement in Britain which drew attention to the important role of language in education. A number of studies were conducted on L1 content classrooms. Some studies focused on specific dimensions of the language used by teachers and learners, for example, the types of teacher questions and the learner responses elicited, the types of learner-talk ("exploratory” versus "final draft”) and the 
mental processes reflected (Barnes, 1969). Some studies aimed at providing a comprehensive description of classroom events and discourse. For example, Sinclair and Coulthard (1975) adopted the notion of "move" to analyze all elements of classroom discourse in order to construct a grammar of spoken discourse. Although Sinclair and Coulthard's work was motivated by linguistic rather than educational concerns, their descriptive framework has been highly influential in classroom discourse research, particularly their analysis of the hierarchical structure of discourse units, namely "acts", "moves", "exchange" and "transaction", and the structure of the "exchange" as consisting of "initiating”, "responding” and "follow-up" moves (IRF).

\section{Major Contributions}

Until the mid-1990s, research on classroom discourse was dominated by an informationprocessing approach to learning based on an input-output model. Learning was understood as a process that took place inside the head of the individual and was separable from the sociocultural contexts of learning. The majority of studies focused on the analysis of language input, interaction and language output. Much of the research conducted in the 1970s and 1980s was "etic" (non-participant's perspective) rather than "emic" (participant's perspective), and a minimalist approach was adopted to the role of context (for reviews of classroom discourse research, see Chaudron, 1988; van Lier, 1988; Allwright \& Bailey, 1991). More recent studies have begun to examine classroom discourse more holistically, and sociocultural perspectives of learning have become increasingly influential.

\section{The Observables: Input, Interaction and Output}

Studies of language input have examined teachers' speech and how it affects learners' language output. Linguistic modifications made by teachers were found to be similar to those used by native speakers (NS) of the target language when talking to non-native speakers (NNS); these have been referred to as "foreigner talk". Early studies focused on the linguistic features of teachers' modified speech with the assumption that such modifications would facilitate comprehension. Subsequent studies, however, have pointed out that interactional modifications resulting from the negotiation of comprehensible input are more important to facilitate language learning. The research focus has shifted to interactional structure and modification devices used by NSs in NSNNS conversations, such as confirmation checks and comprehension checks, which have been used in a number of studies to determine the amount of comprehensible input made available to the learners (Long, 1983; Varonis \& Gass, 1985). The lack of evidence that comprehensible input produces higher quality learner output has led to the "Out Hypothesis" (Swain, 1985) which states that pushing learners to produce comprehensible as well as grammatically accurate output is important for language acquisition because it forces learners to process language at a deeper level and to notice the "holes" in their interlanguage. Subsequent research has further argued for the centrality of output in language acquisition on the basis that it provides opportunities for negotiation of meaning. Negotiation of meaning, which happens when communication failure occurs or when learners are required to complete structured tasks involving information gaps, has 
been considered particularly effective for language acquisition because it connects input, and enhances attention to linguistic form and output (see Interaction Hypothesis proposed by Long, 1996; see also papers collected in Doughty \& Williams, 1998). The findings of studies on the relationship between negotiation of meaning and language acquisition have been somewhat inconclusive, however.

Another strand of research on language input is the study of teachers' questions and their corrective feedback. Studies of teachers' questions in SL/FL classrooms have adopted Barnes' (1969) classification of teacher questions in L1 classrooms, mainly “open” versus "closed" and "pseudo" versus "genuine" questions. They have made similar distinctions between "display questions" (i.e. pseudo-questions) and "referential" questions (i.e. genuine questions). Referential questions have been found to elicit linguistically more complex responses from learners than display questions (Long \& Sato, 1983). Modifications of questions by teachers (comprehension-oriented and response-oriented) and their impact on students' responses have also been investigated. The function of teachers' feedback has been conceived as providing information for learners to confirm or disconfirm their hypotheses about the target language, and the notion of "error" has been reconceptualized from a developmental perspective (Allwright \& Bailey, 1991). More recent research has emphasized the importance of form-focused corrective feedback and "recasts", or reformulations, which rephrase the learners' utterances and correct the errors without changing the meaning of these utterances are considered to facilitate learning, particularly "focused recasts" (see papers collected in Doughty \& Williams, 1998), though research findings have been inconclusive (Lightbown, 2000).

Earlier studies of learner output include learners' turn-taking behavior and oral participation in different classroom settings. Seliger (1983) found that "high-input generators" (HIGs) who generated more input by taking more turns were more effective learners compared with "low-input generators" (LIGs) who took fewer turns. Seliger's position has been questioned on the grounds that important factors such as the cultural backgrounds of the learners which could affect learners' interactional behavior were ignored. Investigations of learners' oral participation have examined the effects of learning arrangements and task types on learner participation. Pair and group interactions were found to generate more negotiation of meaning and a larger variety of speech acts than teacher-fronted settings (Doughty \& Pica, 1986). Tasks which required obligatory information exchange yielded more modified interactions and learner output in pair and group work than those where the information exchange was optional (Plough \& Gass, 1993).

\section{The Unobservables}

The studies reviewed so far pertain mainly to the observable in the classroom. By the late 1980s and early 1990s, it had become clear that studies of the observable needed to be illuminated by the unobservable in the classroom. Researchers suggested that learners' participation in the classroom could be affected by their learning styles, psychological states, cultural backgrounds and beliefs about classroom behavior (Allwright \& Bailey, 
1991; Tsui, 1996). Studies of Asian learners' participation in the classroom have noted that they are less willing to volunteer answers and they take fewer turns than their nonAsian counterparts (Johnson, 1995), and that their observable behaviors are partly shaped by the cultural values, identity and differences of the learners (Duff, 2002). Similarly, the way teachers pose questions and provide feedback, and the kind of interaction they engage with learners are shaped by their conceptions of teaching and learning, and their lived experiences of classroom events. Subsequently, classroom research have adopted an ethnographic approach and have analyzed classroom discourse data in its sociocultural contexts from an emic perspective (van Lier, 1988; Bailey \& Nunan, 1996; Johnson, 1995). Instead of simply focusing on classroom discourse data, a variety of qualitative data, such as lesson plans, teachers' and learners' journals, interviews and stimulated recall protocols have been used to make sense of the discourse data. The wider educational and sociopolitical contexts, such as educational policy, school curriculum, socioeconomic background of learners and school culture, have also been taken into consideration.

\section{Sociocultural Perspectives}

In the 1990s, the shift in research paradigm in general education from information processing to sociocultural perspectives of learning, influenced by the work of the Soviet sociohistorical school (Vygotsky, 1978), began to make an impact on SL research (see Modern Language Journal, Volume 78, 1994). This shift has led to a reconceptualization of language, context and learning in profound ways. A sociocultural theory (SCT) of learning conceptualizes the relationship between the learner and the social world as dialectical rather than dichotomous and as mediated by cultural artifacts, of which language is primary. Learners are not just passive recipients of language input and teachers are not just providers of input. Rather, the learners, the teacher and the sociocultural context in which the discourse takes place are constitutive of what is being learned. Classroom discourse studies based on the input-output model have been criticized for presenting an impoverished and reductionist view of SL/FL learning (see papers collected in Lantolf \& Appel, 1994 and in Lantolf, 2000).

A number of recent classroom-centered studies have adopted SCT, and classroom discourse has been reconceptualized as a major semiotic resource that mediates learning in the classroom. Similarly, curriculum materials, pedagogical activities and tasks have been conceptualized as semiotic resources rather than ways of packaging target language input (see papers collected in Lantolf, 2000). Key concepts in SCT have been used as interpretive frameworks for analyzing classroom discourse data, including the Vygotskian concepts of zone of proximal development (zpd), mediated learning and scaffolding (Bruner, 1983). Several studies have adopted the notion of scaffolded instruction in the learners' zpd and noted that scaffolding facilitates learning only if the teacher is sensitive to the learners' level of linguistic competence and their specific interlanguage features. They have also pointed out that scaffolding can be mutual rather than unidirectional (i.e. from expert to novice), and can be provided by peers, even among very young FL learners (Lantolf \& Appel, 1994). Adopting the notion of mediated learning, Swain (2000) has extended the notion of "output” as external speech. She has 
argued that external speech in collaborative dialogues is a powerful mediational tool for language learning because it encourages learners to reflect on "what is said" in languagerelated episodes while still being oriented to making meaning, and helps learners to monitor their own language use, to notice the gaps in their interlanguage and to set goals for themselves.

\section{Work in Progress}

Current research on classroom discourse appears to cluster around two concerns. One concern is to address issues where research findings have been inconclusive. For example, the conflicting findings of the effect of form-focused corrective feedback such as focused recasts on learners' output have led researchers to investigate other effective strategies. For example, Ellis, Basturkmen and Loewen (2001) have proposed that preemptive rather than corrective focus on form by the learner was more likely to result in learner uptake. Similarly, the inconclusive relationship between negotiation of meaning and language acquisition has led to more recent studies on the relationship between the two. For example, Nakaham, Tyler and van Lier (2001) have found that compared to structured activities such as information gap tasks, unstructured conversations provided more opportunities for language use at a higher level of linguistic complexity even though they triggered fewer negotiation repairs. Foster and Ohta (2005) have found that learners engaged in output modification and form-focused negotiation with supportive peer assistance even when they were not required to fill information gaps or repair communication breakdowns. In addressing these issues, a number of studies have drawn on various theoretical perspectives and have yielded interesting insights.

The second concern is to advance the field by adopting conceptual frameworks in a variety of disciplines, most of which are sociocultural in orientation. A number of classroom discourse studies have drawn on insights from Activity Theory (Lantolf \& Appel, 1994) which conceptualizes goal-oriented human action as part of a larger activity that is driven by motive and shaped by the broader sociocultural system in which the activity is situated. The individual's participation in these socially meaningful activities is mediated by the cultural tools which he or she appropriates. In the course of the interaction, the cultural tools, the nature of the activity and the modes of participation are transformed; the same activity may be realized by different actions mediated by different tools. Conversely, the same action may be driven by different motives, hence realizing different activities. According to this perspective of learning, the same task may be operationalized as different activities with different goal-oriented actions by different learners and by the same learner in different contexts. The dialogic interaction that emerges in task completion plays an important part in shaping the way learners orient themselves to the task and to each other. It is the orientation of learners as agency, not the task per se, that determines the way the task will be performed and the learning that will take place (Lantolf \& Appel, 1994). Hence, tasks should be understood as emergent interactions and not as the packaging of language input.

Also working within the sociocultural paradigm, a number of researchers have adopted an ecological perspective of language learning. For example, van Lier (2000) has emphasized the totality of the relationships between the learner and all other elements or 
participants of the context with which he or she interacts. He has proposed "affordance" as an alternative conception of "input". He has pointed out that the environment makes available opportunities for learners to engage in meaning-making activities with others (a "semiotic budget"), and what is perceived as relevant and acted on by the learner becomes an "affordance". In other words, "input" has been reconceptualized as the linguistic affordances perceived and used by the learner for linguistic action. Input is therefore not something standing outside the learner waiting to be acquired, but rather the interaction between the learner and the environment.

Classroom discourse research has also begun to draw on the conceptual framework of learning as social participation (Lave \& Wenger, 1991; Wenger, 1998), which is also sociocultural in orientation. For example, Donato (2004) has distinguished "interaction" in the second language acquisition literature from the notion of "collaboration" in a social theory of learning which entails mutual engagement in a joint enterprise that is socially meaningful to members of a community of practice. He has noted that the relational dimension of collaboration has been largely ignored in SL/FL classroom research. He has argued that the analysis of discourse generated by isolated task completion in short time frames by group members who are new to group work does not capture the reality of how learning is co-constructed in collaborative work because it takes time to establish relationships. Drawing on the notions of "community of practice" and "legitimate peripheral participation”, Donato has further maintained that the value of collaboration is not to enable learners to acquire more language knowledge, but rather to move from peripheral to full participation as competent members in their communities of practice.

\section{Problems and Difficulties}

From the above review of major contributions to the field, including work in progress, it is apparent that classroom discourse research has made significant progress in addressing issues germane to understanding the complex interplay between factors which impinge on what appear to be simple classroom interchanges. Research on classroom discourse in the last decade has begun to move away from being "data-heavy but theory-light" (Donato, 2004, p. 299). The appropriation of research methods and theoretical frameworks in other disciplines has enriched our understanding of classroom discourse. However, the field is faced with a number of challenges of which only a few obvious ones have been outlined here. One challenge is whether there is a propensity to adopt methodologies without understanding their origins and theory-method relationships, and to use the same terminology with different theoretical assumptions in the discussions. For example, the terms "social" and "context" have been widely used with assumptions which are not shared. Similarly, the term "community" has been used by different researchers in different ways, and the term "community of practice" has been adopted without regard to the way it has been defined in Wenger's theoretical framework (see papers collected in Applied Linguistics, Volume 23(3), 2002). There is also a potential danger of appropriating uncritically some of the key notions in other disciplines. For example, the notion of scaffolding might be taken uncritically as assistance which necessarily leads to more effective learning. As the preceding discussion has shown, scaffolded instruction does not necessarily facilitate learning and over-scaffolding might 
inhibit learning. Another example is the notion of "collaboration" which seems to have been taken as implicated by "interaction". As Donato (2004) has pointed out in his review of current studies of collaborative work, not all forms of classroom interaction are collaborative and conducive to the development of discourse competence.

Another challenge is that the analysis of classroom discourse as situated in its sociohistorical context typically involves an eclectic approach in research methodology and a triangulation of qualitative and quantitative data collected from different sources over a period of time. A rigorous analysis of data requires an iterative process of data interpretation and theory generation which is extremely time-consuming. It is sometimes difficult to present a full account of the research processes within the word limit of a journal article (see for example the exemplars of research methodologies presented in Applied Linguistics, Volume 23(3), 2002). This is probably one of the reasons why, as Donato (2004) has pointed out, research studies from a sociocultural perspective are rich in theoretical concepts but thin on data.

Yet another challenge is the substantiation of claims made about the relationship between language learning and the classroom discourse data analyzed. For example, claims have been made about the effect of input on learners' output, and the effect of pushed output on language acquisition. However, in many cases, there is a lack of substantial evidence to support such claims. In some cases, the evidence is confined to the learners' language output in the adjacent discourse units. There is little evidence of the long-term effect of input on language learning. Similarly, claims made about collaborative learning or coconstruction of knowledge have been based on the analysis of the co-construction of discourse between the teacher and learners and among learners. While one can argue that the discourse is evidence for co-construction of knowledge, it is not always clear that such co-construction facilitates SL/FL learning.

\section{Future Directions}

Since the 1990s, research on classroom discourse has advanced the field in several aspects. First, as Kramch (2002) has observed, there has been a revival of the emphasis on context, an aspect which was minimalized in the 1970s and 1980s. Moreover, instead of focusing on specific aspects of classroom interaction, there is emergent research which takes a more holistic view of classroom interaction, integrates micro- and macroanalyses, and attends to the multiple dimensions of context and the multiple levels of discourse in the classroom. Issues such as power, identity, culture and gender are beginning to appear on the research agenda. For example, Duff (2002) has investigated the co-construction of cultural identity and difference in the classroom where learners are linguistically and socioculturally heterogeneous. The question of the (mis)representation of self in classroom situations through the discourse in which ESL learners are typically engaged is an area which has begun to draw greater attention.

Second, the theoretical frameworks drawn on from neighboring disciplines to illuminate the complexity of classroom data continues to widen. For example, the collection of papers in Lantolf (2000) have advocated a pluralistic approach to SLA and have brought 
together the work of Vygotsky and Bakhtin, social philosophers such as Bourdieu and Habermas, cognitive psychologists such as Rommeveit, and psychologists such as Gibson, Bateson and Bronfrenbrenner. Van Lier (2000) has proposed in that volume that the input-output model should be replaced by an ecological perspective. This has been echoed by Kramsch (2002) who considers an ecological approach to language learning as a powerful way of capturing the symbiotic relationship between the language user and the environment. This approach not only reconciles the tension between language acquisition and language socialization, but also offers a new way of bringing together theoretical frames from other disciplines to enhance our understanding of the complexities of classroom discourse. In the collection of chapters in Kramsch (2002), concepts in the sociology of language such as Goffman's frame analysis and participatory structures have been adopted to analyze the multiple discourse units and levels that are recursively embedded in classroom discourse and the variety of speaker and addressee roles. Papers in the volume point out the need to unravel the cultural, institutional and interactional dimensions of the contexts in which classroom discourse are embedded.

Finally, there are an increasing number of studies which have adopted an eclectic approach to research methodologies in which qualitative and quantitative data are collected from a variety of sources for triangulation, and have provided both etic and emic perspectives in their data analysis.

While classroom discourse research is likely to continue along the trends outlined above, there appear to be three areas which need strengthening. First, as mentioned before, as the field draws on theoretical concepts and research methodologies from a variety of disciplines, it becomes all the more important that the methodologies and terminologies adopted are explicitly and rigorously defined, with full awareness of their theoretical assumptions, irrespective of whether they have been adopted wholesale, extended or redefined.

Second, there has been relatively little in the classroom discourse literature that examines critically the methodological assumptions made in the analysis of data. The issue of Applied Linguistics (Volume 23(3), 2002), which is devoted to methodological issues in the micro-analysis of classroom discourse, is necessary and timely. It presents a collection of papers containing exemplars and critiques of three influential and welldefined methodologies within which classroom discourse analysis have been conducted: ethnography of communication, conversational analysis and systemic functional linguistics, which have emerged respectively from anthropology, sociology and functional linguistics. The discussions do not advocate a particular methodological approach, but rather raise researchers' awareness of methodological issues. More discussion of this kind is necessary to move the field forward.

Third, the teachers' and the learners' voices in the analysis of classroom data continue to be a very important aspect of future research. This is necessary not only because it is crucial for both teachers and learners to be aware of the implications of the classroom discourse that they are involved in co-constructing, but also because they provide an emic perspective on the data, an aspect which still needs strengthening. In particular, as 
Cazden points out, classroom discourse should be the object of focal attention for students as well, because "all students' public words become part of the curriculum for their peers” (Cazden, 2001, p. 169). How learners' engagement in the discourse contributes to the ESL/EFL curriculum constructed in the classroom and how their awareness can be raised are still under-explored.

Amy B. M. Tsui

\section{References}

Allwright, D. (1988). Observation in the Language Classroom. London: Longman.

Allwright, D., \& Bailey, K. (1991). Focus on the Language Classroom. New York: Cambridge University Press.

Bailey, K., \& Nuan, D. (Eds.). (1996). Voices from the Language Classroom. New York: Cambridge University Press.

Barnes, D. (1969). Language in the secondary classroom. In D. Barnes, J. Britton \& H. Rosen (Eds.), Language, the learner and the school (pp. 11-77). Harmondsworth: Penguin.

Bruner, J. (1983). Child's Talk: Learning to use language. New York: Norton.

Cazden, C. (1988 / 2001). Classroom discourse: the language of teaching and learning (1st ed. / 2nd ed.). Portsmouth, NH: Heinemann.

Chaudron, C. (1988). Second Language Classrooms. New York: Cambridge University Press.

Donato, R. (2004). Aspects of Collaboration in Pedagogical Discourse. Annual Review of Applied Linguistics, 24, 284-302.

Doughty, C., \& Williams, J. (Eds.). (1998). Focus on Form in Classroom Second Language Acquisition. Cambridge: Cambridge University Press.

Duff, P. A. (2002). The discursive co-construction of knowledge, identity, and difference: An ethnography of communication in the high school mainstream. Applied Linguistics, 23(3), 289-322.

Flanders, N. A. (1960). Interaction Analysis in the Classroom: A Manual for Observers. Ann Arbor: University of Michigan Press.

Foster, P., \& Ohta, A. S. (2005). Negotiation for Meaning and Peer Assistance in Second Language Classrooms. Applied Linguistics, 26(3), 402-430.

Johnson, K. (1995). Understanding Communication in Second Language Classrooms. New York: Cambridge University Press. 
Kramsch, C. (2002). Introduction: "How can we tell the dancer from the dance?" In C. Kramsch (Ed.), Language Acquisition and Language Socialization: Ecological Perspectives (pp. 1-30). London: Continuum.

Lantolf, J. P. (Ed.). (1994). Modern Language Journal, Volume 78.

Lantolf, J. P. (Ed.) (2000). Sociocultural theory and second language learning. Oxford: Oxford University Press.

Lantolf, J. P., \& Appel, G. (Eds.). (1994). Vygotskian approaches to second language research. Norwood, NJ: Ablex.

Lave, J., \& Wenger, E. (1991). Situated Learning: Legitimate Peripheral Participation. New York: Cambridge University Press.

Lightbown, P. (2000). Anniversary Article: Classroom SLA Research and Second Language Teaching. Applied Linguistics, 21(4), 431-462.

Long, M. (1983). Native-speaker/non-native speaker conversation and the negotiation of comprehensible input. Applied Linguistics, 4, 126-141.

Long, M. H., \& Sato, C. (1983). Classroom foreigner talk discourse: forms and functions of teachers' questions. In H. W. Seliger \& M. H. Long (Eds.), Classroom-oriented research in second language acquisition (pp. 268-285). Rowley, Mass.: Newbury House.

Seliger, H. W. (1983). Learner interaction in the classroom and its effect on language acquisition. In H. W. Seliger \& M. H. Long (Eds.), Classroom oriented research in second language acquisition (pp. 246-267). Rowley, Mass.: Newbury House.

Sinclair, J., \& Coulthard, M. (1975). Towards an Analysis of Discourse. London: Oxford University Press.

Swain, M. (1985). Communicative competence: some roles of comprehensible input and comprehensible ouput in its development. In S. M. Gass \& C. G. Madden (Eds.), Input in Second Language Acquisition. (pp. 235-253). Rowley, Mass.: Newbury House.

Swain, M. (2000). The output hypothesis and beyond: Mediating acquisition through collaborative dialogue. In J. P. Lantolf (Ed.), Sociocultural Theory and Second Language Learning. Oxford: Oxford University Press.

Tsui, A. B. M. (1996). Reticence and anxiety in second language learning. In K. Bailey \& D. Nunan (Eds.), Voices from the Language Classroom. (pp. 145-167). New York: Cambridge University Press.

van Lier, L. (1988). The classroom and the language learner. London: Longman. 
van Lier, L. (2000). From input to affordance: Social-interactive learning from an ecological perspective. In J. P. Lantolf (Ed.), Sociocultural theory and second language learning (pp. 1-26). Oxford: Oxford University Press.

Varonis, E. M., \& Gass, S. (1985). Nonnative / nonnative conversations: A model for negotiation of meaning. Applied Linguistics, 6, 71-90.

Vygotsky, L. S. (1978). Mind in society: the development of higher psychological process. Cambridge, Mass.: Havard University Press.

Wenger, E. (1998). Communities of Practice: Learning, Meaning and Identity.

Cambridge: Cambridge University Press. 